\title{
Biosynthesis of squalene-type triterpenoids in Saccharomyces cerevisiae by expression of CYP505D13 from Ganoderma lucidum
}

Xin Song ${ }^{1 \dagger}$, Han Xiao ${ }^{1 *+} \oplus$, Shangwen Luo ${ }^{2}$, Xiaozheng Wang ${ }^{1}$, Wenfang Wang ${ }^{1}$ and Shuangjun Lin ${ }^{{ }^{*}}$

\begin{abstract}
Background: Squalene-type triterpenoids (STs) are a class of linearized triterpenoids with significant bioactivities, including anti-cancer, anti-oxidative, and anti-inflammatory activities. The efficient biosynthesis of STs has gained increasing attention.

Results: Using Saccharomyces cerevisiae as a heterologous host, we discovered that overexpression of CYP505D13 from Ganoderma lucidum, a famous medicinal mushroom capable of producing various triterpenoids as secondary metabolites, enables the engineered $S$. cerevisiae strain to produce two new STs, 4,8-dihydroxy-22,23-oxidosqualene (ST-1), 8-hydroxy-2,3;22,23-squalene dioxide (ST-2), and a known ST, 2,3; 22,23-squalene dioxide (ST-3), at the respective titers of $3.28 \mathrm{mg} / \mathrm{L}, 13.77 \mathrm{mg} / \mathrm{L}$, and $12.23 \mathrm{mg} / \mathrm{L}$ after $59 \mathrm{~h}$ fermentation. Furthermore, our in vitro enzymatic assay implies that CYP505D13 is involved in the formation of ST-3.
\end{abstract}

Conclusions: This study provides a promising alternative to discover STs and facilitate their efficient bioproduction.

Keywords: Cytochrome P450s (CYPS), Squalene-type triterpenoids (STs), Saccharomyces cerevisiae, Ganoderma lucidum, Synthetic biology

\section{Background}

As a widely distributed class of natural products, triterpenoids are a group of C30 compounds with over 20,000 structurally diverse members (Rascon-Valenzuela et al. 2017). In general, triterpenoids can be cyclic (e.g., lanostane-type, oleane-type, ursane-type, lupanetype) (Chudzik et al. 2015) and linear (squalene-type). Squalene-type triterpenoids (STs) exhibit many promising biological activities, including anti-cancer (CenPacheco et al. 2011; Nguyen et al. 2010), anti-oxidative (Warleta et al. 2010), and anti-inflammatory (Kouam et al. 2012) activities. In addition, many STs are oil-like chemicals with important applications in drug delivery

\footnotetext{
*Correspondence: smallhan@sjtu.edu.cn; linsj@sjtu.edu.cn

${ }^{+}$Xin Song and Han Xiao are co-first authors with equal contribution

1 State Key Laboratory of Microbial Metabolism, Joint International Research Laboratory of Metabolic \& Developmental Sciences,

and Laboratory of Molecular Biochemical Engineering, School of Life Sciences and Biotechnology, Shanghai Jiao Tong University, 800

Dong-chuan Road, Shanghai 200240, China

Full list of author information is available at the end of the article
}

and skin care (Kim and Karadeniz 2012). To fulfill their biotechnological potential, there is a compelling need to efficiently biosynthesize STs.

STs are derived from squalene, which can be produced via the mevalonate (MVA) or 2-C-methyl-D-erythritol 4-phosphate (MEP) pathway (Spanova and Daum 2011). After formation of squalene, a series of post-modifications (e.g., hydroxylation, epoxidation) are responsible for generating the structural diversity of STs (Chen and Wang 2015; Kouam et al. 2012; Nguyen et al. 2010). As the potential candidates for post-modifications of STs, cytochrome P450s (CYPs) catalyze various chemical reactions including chemically challenging stereo- and regio-selective hydroxylation and epoxidation reactions (Wang et al. 2017). In contrast to the role of CYPs in cyclic triterpenoids biosynthesis (Han et al. 2012; Seki et al. 2011; Yasumoto et al. 2017), the contribution of CYPs in ST biosynthesis is relatively unknown. The currently characterized CYPs for cyclic triterpenoids prefer cyclized substrates (Brill et al. 2014; Dai et al. 2019; Han 
et al. 2011), suggesting that other enzymes are responsible for the post-modification of squalene.

Mushrooms are an important group of organisms that possess abundant and diverse CYPs (Chen et al. 2012). As known to produce a myriad of unique triterpenoids, mushrooms play a significant role in the ecosystem as well as in human nutrition and health (Valverde et al. 2015). To circumvent the immature genetic manipulation of mushrooms, we recently developed a synthetic biology platform to identify mushroom-derived CYPs using Saccharomyces cerevisiae as a screening host (Wang et al. 2018). We chose S. cerevisiae because: (i) it is a genetically tractable host; (ii) it naturally produces direct triterpenoid precursors (e.g., squalene, lanosterol); (iii) it has subcellular organelles (e.g., endoplasmic reticulum) to support the function of membrane-bounded CYPs; and (iv) its well-characterized endogenous CYPs are less likely to interfere with exogenous ones (Kelly et al. 2001; Xiao et al. 2019). This strategy enabled the discovery of cyp5150l8 from a famous traditional medicinal mushroom, Ganoderma lucidum, as the first CYP responsible for biosynthesis of the cyclic triterpenoid ganoderic acid HLDOA (Wang et al. 2018).

Along with the above mentioned paradigm, we discovered that overexpression of cyp505d13 from G. lucidum in S. cerevisiae YL-T3 yielded many compounds as compared to the control strain. Three major compounds were purified and identified to be STs, including two new STs. We further analyzed the production profile of these STs by the engineered yeast strain. This work is valuable towards STs' discovery and their efficient bioproduction for biotechnological purposes.

\section{Materials and methods}

\section{Strains and media}

Escherichia coli DH5 $\alpha$ (Tiangen Biotech, Beijing, China) was used in routine DNA cloning. CYP505D13 was overexpressed in either E. coli Rosseta $^{\text {TM }}$ (DE3) (Weidi Biotechnology, Shanghai, China) or S. cerevisiae YL-T3 (BY4742,

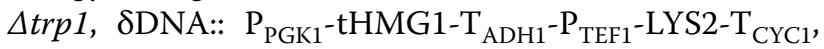

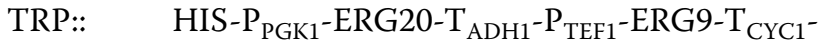
$\mathrm{P}_{\mathrm{TDH} 3}-\mathrm{ERG1} \mathrm{T}_{\mathrm{TPL} 1}$ ) (Wang et al. 2018). Engineered E. coli strains were grown in LB medium containing $50 \mu \mathrm{g} / \mathrm{mL}$ kanamycin and $34 \mu \mathrm{g} / \mathrm{mL}$ chloramphenicol at $37^{\circ} \mathrm{C}$ and $220 \mathrm{rpm}$. Engineered yeast strains were grown either in SC-His-Ura-Leu medium or in YPD medium at $30{ }^{\circ} \mathrm{C}$ and $220 \mathrm{rpm}$.

\section{Construction of plasmids and strains}

The coding sequence (CDS) of cyp505d13 was cloned using primer pair GL17184-F and GL17184-R with the cDNA of G. lucidum as template (Additional file 1: Table S1). G. lucidum cDNA was prepared as described
(Wang et al. 2018). Cyp505d13 was ligated to PmeIlinearized pRS426-HXT7p-FBA1t (Wang et al. 2018) to yield plasmid pRS426-HXT7p-CYP505D13-FBA1t as described in SoSoo cloning kit (Tsingke, Beijing, China). Alternatively, the CDS of cyp505d13 was cloned using primer pair 28a-GL17184-F and 28a-GL17184R (Additional file 1: Table S1), and was ligated to NcoI \& Xhol-linearized pET28a to yield plasmid pET28aCYP505D13 as described in Ezmax One-Step kit (Tolo Biotech, Shanghai, China). Plasmids pRS426-HXT7pCYP505D13-FBA1t and pRS425-TEF1p-PGK1t were transformed into $S$. cerevisiae YL-T3 using standard lithium acetate method (Gietz and Schiestl 2007) to yield the YL-T3-CYP505D13 strain. YL-T3 containing void plasmids pRS426-HXT7p-FBA1t and pRS425-TEF1p-PGK1t was served as the control strain for the experiments presented in this work (Wang et al. 2018). Plasmid pET28aCYP505D13 was transformed into E. coli Rosseta $^{\text {TM }}$ (DE3) to yield strain Rosseta-CYP505D13.

\section{UPLC-MS and NMR analyses}

UPLC-MS and NMR analyses were carried out as previously reported (Wang et al. 2018) with a minor modification in the UPLC condition. The mobile phase A contained water/formic acid (100: $0.1 \mathrm{v} / \mathrm{v}$ ) and mobile phase B contained methanol/formic acid (100: $0.1 \mathrm{v} / \mathrm{v})$. A linear gradient of $70 \%$ B to $100 \%$ B in $10.5 \mathrm{~min}$ at $0.4 \mathrm{~mL} /$ min was adopted. Compounds were detected at a wavelength of $210 \mathrm{~nm}$.

\section{Extraction and purification of compounds 1, 2, and 3}

YL-T3- CYP505D13 was cultured in YPD medium for the purification of $\mathbf{1}, \mathbf{2}$, and $\mathbf{3}$. After 4 days of fermentation, $1.1 \mathrm{~kg}$ (wet cell weight) of cells was collected after centrifugation $\left(3214 g, 5 \mathrm{~min}, 4^{\circ} \mathrm{C}\right.$ ) and extracted twice with $22 \mathrm{~L}$ of ethyl acetate, each time for $1 \mathrm{~h}$ by magnetic stirrer-assisted extraction. Thirty grams of crude extract was obtained after collection and evaporation of the organic phase. The crude extract (15 g) was subjected to silica gel column chromatography $(6 \times 40 \mathrm{~cm})$ and eluted with a petroleum ether-ethyl acetate system. Fractions containing 1, 2, and 3 were further purified by preparative HPLC (Waldbronn, Germany) equipped with a preparative Kromasil 100-10-C18 column $(20 \times 250 \mathrm{~mm})$ (Kromasi, Sweden). For preparative HPLC, the mobile phase A was $100 \%$ water and mobile phase B was acetonitrile. For compound 1, a linear gradient of $85-90 \%$ B in $30 \mathrm{~min}$ at $10 \mathrm{~mL} / \mathrm{min}$ was adopted, and $5.2 \mathrm{mg}$ of purified 1 was obtained by collecting elutes from 29 to $30 \mathrm{~min}$. For compound 2, a linear gradient of $90-95 \%$ B in $30 \mathrm{~min}$ at $10 \mathrm{~mL} / \mathrm{min}$ was chosen, yielding $20.3 \mathrm{mg}$ of purified 2 by collecting elutes from 18.6 to $21.2 \mathrm{~min}$. For compound 3 , a linear gradient of $95-100 \% \mathrm{~B}$ in $10 \mathrm{~min}$ at $10 \mathrm{~mL} / \mathrm{min}$ 
was adopted, and $35.6 \mathrm{mg}$ of purified 3 was obtained by collecting elutes from 25.7 to $28 \mathrm{~min}$.

\section{Yeast fermentation, analyses of cell growth and product accumulation}

For shake-flask fermentations, a single colony was picked into a $15 \mathrm{~mL}$ tube containing $4 \mathrm{~mL}$ of SC-His-Ura-Leu medium and grown to an $\mathrm{OD}_{600}$ of 3-4. Then, $1 \mathrm{~mL}$ of these starter cultures was diluted into $50 \mathrm{~mL}$ of SC-HisUra-Leu medium in a $250 \mathrm{~mL}$ shake flask and grown to an $\mathrm{OD}_{600}$ of 2 . These seed cultures were used to inoculate $50 \mathrm{~mL}$ of YPD medium in $250 \mathrm{~mL}$ shake flasks to achieve an initial $\mathrm{OD}_{600}$ of 0.05 .

For fermentation in $10 \mathrm{~L}$ stirred bioreactor (T\&J Bioengineering, Shanghai, China), $140 \mathrm{~mL}$ of seed cultures from shake flasks was inoculated into $6.5 \mathrm{~L}$ of YPD medium and agitated by a standard six-blade turbine impeller at a speed of $300 \mathrm{rpm}$ and an aeration rate of 1.2 vvm at $30{ }^{\circ} \mathrm{C}$. Cell growth, glucose, ethanol, and acetate concentrations were determined as previously reported (Wang et al. 2018). For detection of compounds 1, 2, and 3, $20 \mathrm{~mL}$ of yeast culture was mixed with an equivalent volume of ethyl acetate and shaken for $30 \mathrm{~min}(220 \mathrm{rpm})$. The organic phase was collected by centrifugation and evaporation, and the resulting residue was re-dissolved in methanol for HPLC (Agilent, Waldbronn, Germany) analysis. Samples were assayed on an Agilent SB-C18 column $(5 \mu \mathrm{m}, 4.6 \mathrm{~mm} \times 250 \mathrm{~mm})$. Mobile phase A was $100 \%$ water, and mobile phase B contained methanol/ acetic acid (100: $0.1 \mathrm{v} / \mathrm{v})$. A linear gradient for $80 \%$ to $100 \% \mathrm{~B}$ in $30 \mathrm{~min}$ at $1 \mathrm{~mL} / \mathrm{min}$ was adopted.

\section{Expression of CYP505D13 in E. coli}

A single colony from E. coli strain Rosseta-CYP505D13 was picked into a $15 \mathrm{~mL}$ tube containing $4 \mathrm{~mL}$ of $\mathrm{LB}$ medium and appropriate antibiotics, and grown to an $\mathrm{OD}_{600}$ of 2.5 at $37^{\circ} \mathrm{C}$ with $220 \mathrm{rpm}$. Then, $9 \mathrm{~mL}$ of these starter cultures was diluted into $800 \mathrm{~mL}$ of LB medium in a $2 \mathrm{~L}$ shake flask and grown to an $\mathrm{OD}_{600}$ of 0.8 . Then, CYP expression was induced with $0.5 \mathrm{mM}$ isopropyl $\beta$-D1-thiogalactopyranoside (IPTG) at $16{ }^{\circ} \mathrm{C}$ and $220 \mathrm{rpm}$ for another 14-18 h. Meanwhile, $0.5 \mathrm{mM}$ 5-aminolevulinic acid hydrochloride was added to promote heme biosynthesis.

\section{CYP spectral assay}

A total of $10 \mathrm{mg}$ protein from E. coli cell lysates was used for CYP spectral assay as described (Guengerich et al. 2009). To obtain E. coli cell lysates, about $12 \mathrm{~g}$ (wet cell weight) of $E$. coli cells after IPTG induction were suspended in $120 \mathrm{~mL}$ extraction buffer $(50 \mathrm{mM}$ Tris- $\mathrm{HCl}$ (pH 7.5), $20 \mathrm{mM} \beta$-mercaptoethanol, 1 mM EDTA, 20\% glycerol), and broken by a Nano homogenizer (ATS Engineering Ltd., Suzhou, China) (cycle 2, 800 bar, $4{ }^{\circ} \mathrm{C}$ ).

\section{In vitro enzymatic assay}

Microsomal isolation was performed as previously reported (Wang et al. 2018). The enzymatic assay was carried out in $0.5 \mathrm{~mL}$ of extraction buffer containing $1.25 \mathrm{mg}$ protein from $E$. coli cell lysates or $1 \mathrm{mg}$ microsomal protein from yeast strains, $1 \mu \mathrm{M}$ FMN, $1 \mu \mathrm{M}$ FAD, $2 \mathrm{mM}$ $\mathrm{NADPH}$, and $50 \mu \mathrm{M}$ substrate. The enzymatic reaction was carried out at $30^{\circ} \mathrm{C}$ and $120 \mathrm{rpm}$ for $2 \mathrm{~h}$. For the control experiments, the same amount of protein from cell lysates of Rosseta-CYP505D13 or YL-T3-CYP505D13containing microsomes was inactivated by incubation at $80{ }^{\circ} \mathrm{C}$ for $10 \mathrm{~min}$ prior to the assay. Alternatively, the same amount of microsomal protein from the control yeast strain (YL-T3 containing void plasmids) was used. The product was extracted by $0.5 \mathrm{~mL}$ of ethyl acetate for three times after incubation at $30^{\circ} \mathrm{C}$ and $120 \mathrm{rpm}$ for $2 \mathrm{~h}$. The ethyl acetate layer was collected, evaporated, and redissolved in methanol for HPLC analysis.

\section{Results and discussion}

Overexpression of CYP505D13 generates many new UPLC detectable peaks as compared to the control strain

Since CYP505D13 from G. lucidum was co-expressed with lanosterol synthase (Chen et al. 2012), it was initially considered as a candidate of lanosterol oxidase for biosynthesis of ganoderic acids, a group of lanostane-type triterpenoids (Wang et al. 2018). To test the function of CYP505D13, the CDS of cyp505d13 was cloned into a yeast expression vector pRS426-HXT7p-FBA1t and transformed into S. cerevisiae YL-T3 to generate strain YL-T3-CYP505D13, in accordance with our previous paradigm for discovering lanosterol oxidase (Wang et al. 2018).

As shown in Fig. 1a, 20 new peaks were detected in the cell extracts of YL-T3-CYP505D13 after $96 \mathrm{~h}$ shake-flask fermentation compared to the control strain (YL-T3 harboring void plasmids). Except for peak 18 with a detected $\mathrm{m} / \mathrm{z}$ at 383 , the other 19 peaks are likely correspond to ST products with the primary $\mathrm{m} / \mathrm{z}$ values at 423 (peaks 10 , 11, 12, 13), 425 (peaks 17, 19, 20), 439 (peaks 1, 2, 4, 7, 8, 9), 441 (peaks 14, 15, 16), and 457 (peaks 3, 5, 6) (Fig. 1 and Additional file 2: Fig. S1). The peaks with $m / z 423$ and 425 are likely hydrogenation products of 2,3-oxidosqualene, and the peaks with $m / z 439$ and 441 may be the hydrogenation products of oxidized 2,3-oxidosqualene. Lastly, the peaks with $m / z 457$ probably correspond to the oxidized products of the peaks with $m / z 441$. 

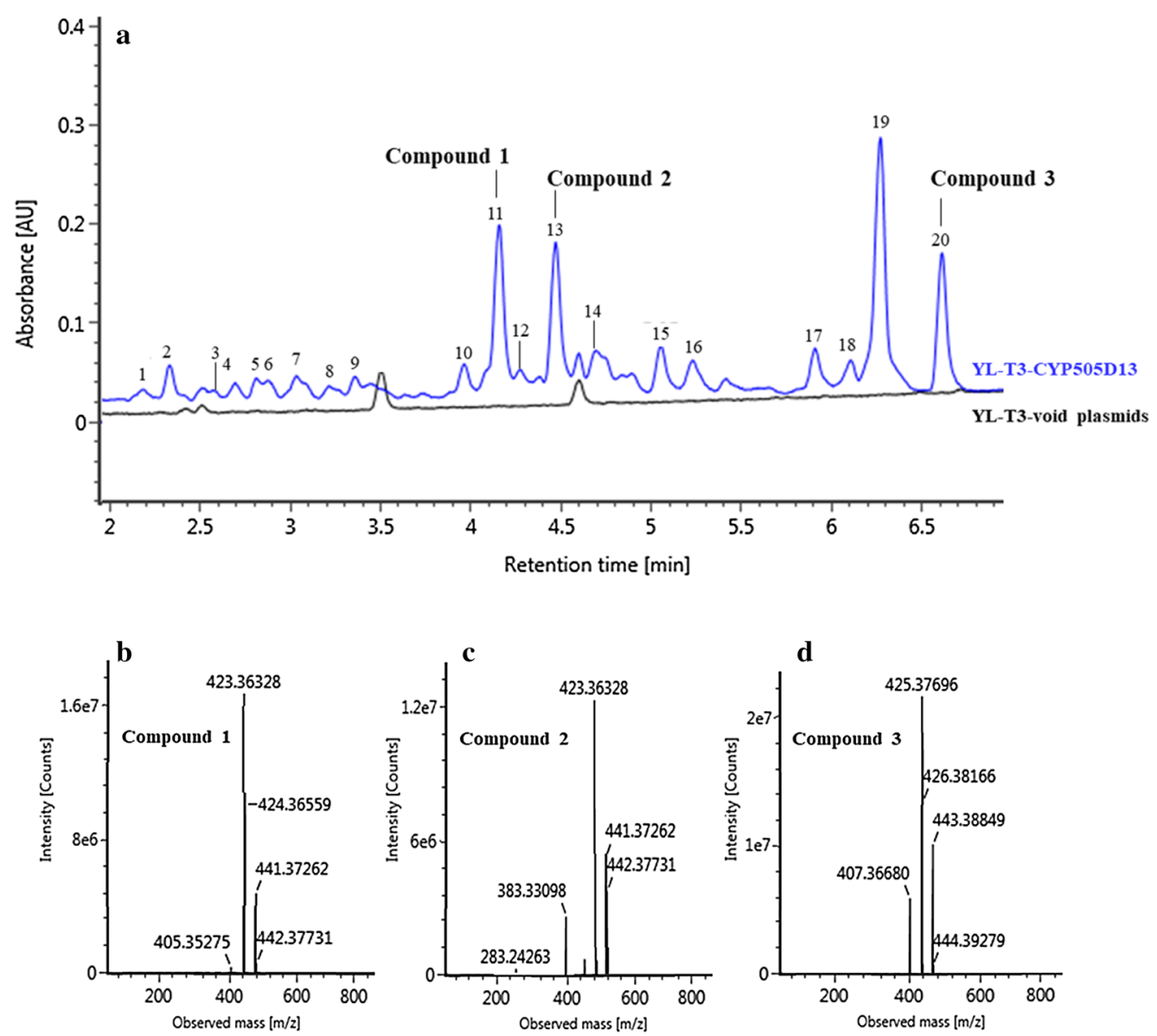

Fig. 1 UPLC-MS analysis of $96 \mathrm{~h}$ fermentation extract of YL-T3-CYP505D13. a UPLC analysis of extracts of YL-T3-CYP505D13 (blue line) and the control strain (black line); b-d MS spectra of compound 1, compound 2 and compound 3 as indicated in a

\section{Identification of $\mathbf{1}, \mathbf{2}$ and $\mathbf{3}$ as STs}

To determine the chemical structures of new compounds that were generated as a result of CYP505D13 overexpression, $6.9 \mathrm{mg}, 20.3 \mathrm{mg}$, and $65.4 \mathrm{mg}$ of $\mathbf{1}, \mathbf{2}$, and 3, corresponding to peaks 11,13 , and 20 were extracted and purified (Fig. 1a).

The molecular formula of $\mathbf{3}$ was established to be $\mathrm{C}_{30} \mathrm{H}_{50} \mathrm{O}_{2}$ based on high resolution atmospheric pressure chemical ionization (HRAPCI) MS $(m / z 443.3885$, calcd 443.3884 $[\mathrm{M}+\mathrm{H}]^{+}$) and NMR analyses (Fig. 1d). The ${ }^{1} \mathrm{H}$ NMR spectrum showed eight singlet methyl groups $\left(\delta_{\mathrm{H}}\right.$ $\left.1.30, \mathrm{H}-1 / 25 / 24 / 30 ; \delta_{\mathrm{H}} 1.25, \mathrm{H}-27 / 28 ; \delta_{\mathrm{H}} 1.61, \mathrm{H}-26 / 29\right)$, two methylene groups $\left(\delta_{\mathrm{H}} 2.70, \mathrm{H}-3 / 22\right)$, four olefinic protons $\left(\delta_{\mathrm{H}} 5.15, \mathrm{H}-7 / 11 / 14 / 18\right)$ (Additional file 4: Fig. S3C, Table 3). With the aid of DEPT and HSQC spectra, ${ }^{13} \mathrm{C}$ NMR showed 30 carbons including eight $\mathrm{CH}_{3}\left(\delta_{\mathrm{C}} 24.9, \mathrm{C}-1 / 25 / 24 / 30 ; \delta_{\mathrm{C}} 18.8, \mathrm{C}-27 / 28 ; \delta_{\mathrm{C}} 16.0\right.$, $\mathrm{C}-26 / 29)$, ten $\mathrm{CH}_{2}\left(\delta_{\mathrm{C}} 27.5, \mathrm{C}-4 / 21 ; \delta_{\mathrm{C}} 36.3, \mathrm{C}-5 / 20 ; \delta_{\mathrm{C}}\right.$ $26.7, \mathrm{C}-8 / 17 ; \delta_{\mathrm{C}} 39.7, \mathrm{C}-9 / 16 ; \delta_{\mathrm{C}} 28.2$, C-12/13), two oxygenated $\mathrm{CH}\left(\delta_{\mathrm{C}} 64.2, \mathrm{C}-3 / 22\right)$, and eight olefin carbons
(Additional file 3: Fig. S2C, Additional file 5: Fig. S4C, Additional file 6: Fig. S5C and Table 3). Combined analysis of other 2D NMR spectra (HMBC and ${ }^{1} \mathrm{H}-{ }^{1} \mathrm{H}$ COSY) confirmed this compound to be 2,3;22,23-squalene dioxide (José-Luis et al. 1992) (Additional file 7: Fig. S6C and Additional file 8: Fig. S7C). Henceforth, this compound will be known as ST-3.

The molecular formula of $\mathbf{2}$ was established as $\mathrm{C}_{30} \mathrm{H}_{50} \mathrm{O}_{3}$ based on HRAPCIMS $(\mathrm{m} / z$ 441.3726, calcd 441.3727 $\left[\mathrm{M}+\mathrm{H}-\mathrm{H}_{2} \mathrm{O}\right]^{+}$) and NMR analyses (Fig. 1c). The 1D NMR data of $\mathbf{2}$ were very similar to that of $\mathbf{3}$ (Additional file 3: Fig. S2B, C, Additional file 4: Fig. S3B, C, Additional file 5: Fig. S4B, C, Additional file 6: Fig. S5B, C, Tables 2 and 3). An obvious difference was an additional oxygenated $\mathrm{CH}\left(\delta_{\mathrm{C}} 65.6, \mathrm{C}-8\right.$ and $\delta_{\mathrm{H}} 4.42$, $\mathrm{H}-8$ ) found in 2 (Additional file 3: Fig. S2B, C, Additional file 4: S3B, C, Tables 2 and 3). ${ }^{1} \mathrm{H}-{ }^{1} \mathrm{H}$ COSY correlation between $\mathrm{H}-7\left(\delta_{\mathrm{H}} 5.25\right) / \mathrm{H}-8\left(\delta_{\mathrm{H}} 4.42\right) / \mathrm{H}-9\left(\delta_{\mathrm{H}} 2.14\right)$ (Additional file 8: Fig. $\mathrm{S} 7 \mathrm{~B}$ and $\mathrm{C})$, together with $\mathrm{HMBC}$ from H-8 to C-6 and C-10 (Additional file 7: Fig. S6B and C), 
Table 1 NMR data of 1

\begin{tabular}{|c|c|c|c|c|}
\hline No & $\delta_{H}($ mult, $J / H z)$ & $\delta_{c}(\mathrm{DEPT})$ & ${ }^{1} \mathrm{H}-{ }^{1} \mathrm{H}$ COSY & $\mathrm{gHMBC}$ \\
\hline 1 & 1.68 & $18.4(\mathrm{~s})$ & & 3,25 \\
\hline 2 & & 131.8(s) & & \\
\hline 3 & $5.26(\mathrm{~m})$ & 129.3(d) & 4 & 5 \\
\hline 4 & $4.42(\mathrm{~m})$ & $65.8(d)$ & 3,5 & 2 \\
\hline 5 & $2.10(\mathrm{~m})$ & $27.4(\mathrm{t})$ & 4 & 3,26 \\
\hline 6 & & 137.3(s) & & \\
\hline 7 & $5.22(\mathrm{~m})$ & $128.7(d)$ & 8 & $5,9,26$ \\
\hline 8 & $4.42(m)$ & $65.8(d)$ & 7,9 & 6,10 \\
\hline 9 & $2.12(\mathrm{~m})$ & $48.5(\mathrm{t})$ & 8 & $7,11,27$ \\
\hline 10 & & 131.8(s) & & \\
\hline 11 & $5.21(\mathrm{~m})$ & $128.0(d)$ & 12 & $9,13,27$ \\
\hline 12 & $1.67(\mathrm{~m})$ & $28.4(\mathrm{t})$ & 11,13 & 10,14 \\
\hline 13 & $2.08(m)$ & $28.2(\mathrm{t})$ & 12,14 & 11,15 \\
\hline 14 & $5.15(\mathrm{~m})$ & 127.6(d) & 13 & 12,28 \\
\hline 15 & & 134.9(s) & & \\
\hline 16 & $2.02(\mathrm{~m})$ & $39.7(t)$ & 17 & $14,28,18$ \\
\hline 17 & $2.03(\mathrm{~m})$ & $26.0(\mathrm{t})$ & 16,18 & 15,19 \\
\hline 18 & $5.12(\mathrm{~m})$ & $124.6(d)$ & 17 & $16,20,29$ \\
\hline 19 & & 135.5(s) & & \\
\hline 20 & $2.10(\mathrm{~m})$ & $36.4(\mathrm{t})$ & 21 & 29,22 \\
\hline 21 & 1.62(m) & $26.7(t)$ & 20,22 & 19,23 \\
\hline 22 & $2.68(m)$ & $64.2(\mathrm{~d})$ & 20 & $20,24,30$ \\
\hline 23 & & $58.6(\mathrm{~s})$ & & \\
\hline 24 & $1.30(\mathrm{~s})$ & $25.1(q)$ & & 22,30 \\
\hline 25 & $1.30(\mathrm{~s})$ & $25.1(q)$ & & 1,3 \\
\hline 26 & $1.67(\mathrm{~s})$ & $16.4(q)$ & & 5,7 \\
\hline 27 & $1.65(\mathrm{~s})$ & $16.8(q)$ & & 9,11 \\
\hline 28 & $1.65(\mathrm{~s})$ & $16.4(q)$ & & 14,16 \\
\hline 29 & $1.60(\mathrm{~s})$ & $16.1(q)$ & & 18,20 \\
\hline 30 & $1.26(\mathrm{~s})$ & $18.9(q)$ & & 22,24 \\
\hline
\end{tabular}

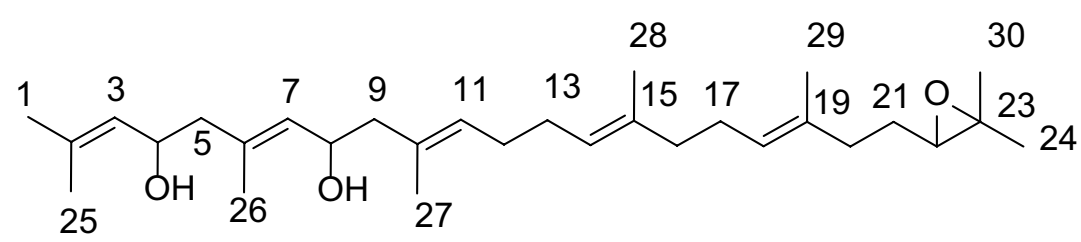

indicated a hydroxyl group at C-8. Finally, 2 was identified as 8-hydroxy-2,3;22,23-squalene dioxide. This novel compound will be known as ST-2 from here on.

The molecular formula of $\mathbf{1}$ was established as $\mathrm{C}_{30} \mathrm{H}_{50} \mathrm{O}_{3}$ based on HRAPCIMS ( $\mathrm{m} / z$ 441.3726, calcd 441.3727 $\left[\mathrm{M}+\mathrm{H}-\mathrm{H}_{2} \mathrm{O}\right]^{+}$) and NMR analyses (Fig. 1b). The 1D NMR data of $\mathbf{1}$ were very similar to that of $\mathbf{2}$ and 3 (Additional file 3: Fig. S2, Additional file 4: Fig. S3, Additional file 5: Fig. S4, Additional file 6: Fig. S5,
Tables 1, 2 and 3). Compared with the ${ }^{13} \mathrm{C}$ NMR spectrum of 2 , there were two new olefin carbons in $\mathbf{1}\left(\delta_{\mathrm{C}}\right.$ $129.3, \mathrm{C}-3$ and $\left.\delta_{\mathrm{H}}, 5.26, \mathrm{H}-3 ; \delta_{\mathrm{C}} 131.8, \mathrm{C}-2\right)$ and an oxygenated $\mathrm{CH}\left(\delta_{\mathrm{C}} 65.8, \mathrm{C}-4\right.$ and $\left.\delta_{\mathrm{H}}, 4.42, \mathrm{H}-4\right)$ (Additional file 3: Fig. S2 A, B, Additional file 4: Fig. S3 A, B, Tables 1 and 2). ${ }^{1} \mathrm{H}-{ }^{1} \mathrm{H}$ COSY correlation between $\mathrm{H}-3\left(\delta_{\mathrm{H}}, 5.26\right)$ and $\mathrm{H}-4\left(\delta_{\mathrm{H}}, 4.42\right)$ suggested an oxygenated $\mathrm{CH}$ at $\mathrm{C}-3$ (Additional file 8: Fig. S7, Tables 1 and 2). In addition, an oxygenated $\mathrm{CH}\left(\delta_{\mathrm{C}} 64.2, \mathrm{C}-3\right.$ and $\left.\delta_{\mathrm{H}} 2.70, \mathrm{H}-3\right)$ in 2 was 
Table 2 NMR data of 2

\begin{tabular}{|c|c|c|c|c|}
\hline No & $\delta_{H}($ mult, $J / H z)$ & $\delta_{c}(\mathrm{DEPT})$ & ${ }^{1} \mathrm{H}-{ }^{1} \mathrm{H} \operatorname{COSY}$ & gHMBC \\
\hline 1 & $1.30(\mathrm{~s})$ & $24.9(q)$ & & 3,25 \\
\hline 2 & & $58.4(\mathrm{~s})$ & & \\
\hline 3 & $2.70(\mathrm{~m})$ & $64.2(d)$ & 4 & 5 \\
\hline 4 & $1.62(\mathrm{~m})$ & $27.5(\mathrm{t})$ & 3,5 & 2,6 \\
\hline 5 & $2.09(\mathrm{~m})$ & $36.3(\mathrm{t})$ & 4 & 3,26 \\
\hline 6 & & 137.1(s) & & \\
\hline 7 & $5.25(\mathrm{~m})$ & $128.7(d)$ & 8 & $5,9,26$ \\
\hline 8 & $4.42(m)$ & $65.6(d)$ & 7,9 & 6,10 \\
\hline 9 & $2.14(\mathrm{~m})$ & $48.2(\mathrm{t})$ & 8 & $7,11,27$ \\
\hline 10 & & $131.6(\mathrm{~s})$ & & \\
\hline 11 & $5.19(\mathrm{~m})$ & 127.8(d) & 12 & $9,13,27$ \\
\hline 12 & $1.70(\mathrm{~m})$ & $28.2(\mathrm{t})$ & 11,13 & 10,14 \\
\hline 13 & $2.08(m)$ & $28.0(\mathrm{t})$ & 12,14 & 11,15 \\
\hline 14 & 5.14(m) & $124.8(d)$ & 13 & 12,28 \\
\hline 15 & & 134.0(s) & & \\
\hline 16 & $1.98(\mathrm{~m})$ & $39.6(t)$ & 17 & $14,28,18$ \\
\hline 17 & $2.07(\mathrm{~m})$ & $26.6(t)$ & 16,18 & 15,19 \\
\hline 18 & $5.10(\mathrm{~m})$ & $124.0(d)$ & 17 & $16,20,29$ \\
\hline 19 & & 135.5(s) & & \\
\hline 20 & $2.09(\mathrm{~m})$ & $36.3(\mathrm{t})$ & 21 & 29,22 \\
\hline 21 & 1.62(m) & $27.2(t)$ & 20,22 & 19,23 \\
\hline 22 & $2.69(\mathrm{~m})$ & $64.0(d)$ & 20 & $20,24,30$ \\
\hline 23 & & $58.4(\mathrm{~s})$ & & \\
\hline 24 & $1.25(\mathrm{~s})$ & $18.7(q)$ & & 22,30 \\
\hline 25 & $1.30(\mathrm{~s})$ & $24.9(q)$ & & 1,3 \\
\hline 26 & $1.70(\mathrm{~s})$ & $16.6(q)$ & & 5,7 \\
\hline 27 & $1.70(\mathrm{~s})$ & $16.6(q)$ & & 9,11 \\
\hline 28 & $1.61(\mathrm{~s})$ & $16.1(q)$ & & 14,16 \\
\hline 29 & $1.59(\mathrm{~s})$ & $16.0(q)$ & & 18,20 \\
\hline 30 & $1.25(\mathrm{~s})$ & $18.7(q)$ & & 22,24 \\
\hline
\end{tabular}

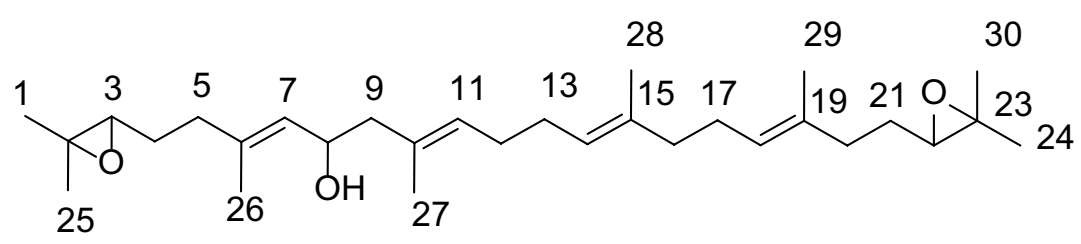

absent in 1 (Additional file 3: Fig. S2, Additional file 4: Fig. S3, Tables 1 and 2). These data showed that a double bond was formed between $\mathrm{C}-2$ and $\mathrm{C}-3$ and a hydroxyl group at $\mathrm{C}-4$, as supported by $\mathrm{HMBC}$ from $\mathrm{H}-4$ to $\mathrm{C}-2$ and C-6 (Fig. S6). 1 was identified as 4,8-dihydroxy22,23-oxidosqualene, which is a novel compound and henceforth known as ST-1.
Heterologous bioproduction of ST-1, ST-2, and ST-3

The fed batch fermentation of YL-T3-CYP505D13 was performed in a $10 \mathrm{~L}$ bioreactor. After a lag phase of $9.5 \mathrm{~h}$, the glucose was completely consumed within $24 \mathrm{~h}$ while the $S$. cerevisiae cells grew rapidly before $45 \mathrm{~h}$ (Fig. 2a). The dissolved oxygen (DO) decreased quickly after $15 \mathrm{~h}$, dropping to the lowest level of $9 \%$ of air saturation at $31 \mathrm{~h}$ before quickly rebounding to $70 \%$ after $40 \mathrm{~h}$ (Fig. 2b). The pH changed between 5.4 and 7.0 during 
Table 3 NMR data of 3

\begin{tabular}{|c|c|c|c|c|}
\hline No & $\delta_{H}($ mult, $J / H z)$ & $\delta_{c}(\mathrm{DEPT})$ & ${ }^{1} \mathrm{H}-{ }^{1} \mathrm{H}$ COSY & $\mathrm{gHMBC}$ \\
\hline 1 & $1.30(\mathrm{~s})$ & $24.9(q)$ & & 3,25 \\
\hline 2 & & $58.4(\mathrm{~s})$ & & \\
\hline 3 & $2.70(\mathrm{~m})$ & $64.2(d)$ & 4 & 5 \\
\hline 4 & $1.59(\mathrm{~m})$ & $27.5(\mathrm{t})$ & 3,5 & 2,6 \\
\hline 5 & $2.08(m)$ & $36.3(\mathrm{t})$ & 4 & 3,26 \\
\hline 6 & & 135.0(s) & & \\
\hline 7 & $5.15(\mathrm{~m})$ & $124.4(d)$ & 8 & $5,9,26$ \\
\hline 8 & $2.08(\mathrm{~m})$ & $26.7(\mathrm{t})$ & 7,9 & 6,10 \\
\hline 9 & 1.98(m) & $39.7(t)$ & 8 & $7,11,27$ \\
\hline 10 & & 134.0(s) & & \\
\hline 11 & $5.15(\mathrm{~m})$ & $124.9(d)$ & 12 & $9,13,27$ \\
\hline 12 & $2.0(\mathrm{~m})$ & $28.2(\mathrm{t})$ & 11,13 & 10,14 \\
\hline 13 & $2.0(\mathrm{~m})$ & $28.2(\mathrm{t})$ & 12,14 & 11,15 \\
\hline 14 & $5.15(\mathrm{~m})$ & $124.9(d)$ & 13 & 12,28 \\
\hline 15 & & 134.0(s) & & \\
\hline 16 & $1.98(\mathrm{~m})$ & $39.7(t)$ & 17 & $14,28,18$ \\
\hline 17 & $2.08(m)$ & $26.7(\mathrm{t})$ & 16,18 & 15,19 \\
\hline 18 & $5.15(\mathrm{~m})$ & $124.4(d)$ & 17 & $16,20,29$ \\
\hline 19 & & 135.0(s) & & \\
\hline 20 & $2.08(\mathrm{~m})$ & $36.3(\mathrm{t})$ & 21 & 29,22 \\
\hline 21 & $1.59(\mathrm{~m})$ & $27.5(t)$ & 20,22 & 19,23 \\
\hline 22 & $2.70(\mathrm{~m})$ & $64.2(\mathrm{~d})$ & 20 & $20,24,30$ \\
\hline 23 & & $58.4(\mathrm{~s})$ & & \\
\hline 24 & $1.30(\mathrm{~s})$ & $24.9(q)$ & & 22,30 \\
\hline 25 & $1.30(\mathrm{~s})$ & $24.9(q)$ & & 1,3 \\
\hline 26 & $1.61(\mathrm{~s})$ & $16.0(q)$ & & 5,7 \\
\hline 27 & $1.25(\mathrm{~s})$ & $18.8(q)$ & & 9,11 \\
\hline 28 & $1.25(\mathrm{~s})$ & $18.8(q)$ & & 14,16 \\
\hline 29 & $1.61(\mathrm{~s})$ & $16.0(q)$ & & 18,20 \\
\hline 30 & $1.30(\mathrm{~s})$ & $24.9(q)$ & & 22,24 \\
\hline
\end{tabular}

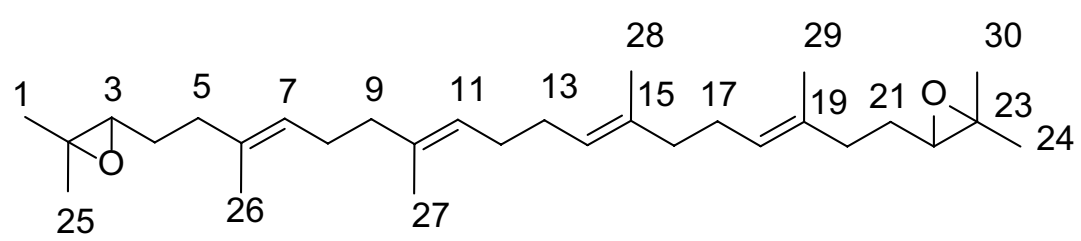

the fermentation process (Fig. 2b). Production of ethanol and acetic acid, together with their consumption were all observed (Fig. 2c). After ST-3 production was first detected at $9.5 \mathrm{~h}$, production of ST-2 and ST-3 were subsequently observed at $24 \mathrm{~h}$ and $45 \mathrm{~h}$, respectively (Fig. 2d). The highest production of ST-1, ST-2, and ST-3 were achieved at $59 \mathrm{~h}, 45 \mathrm{~h}$ and $59 \mathrm{~h}$, reaching $3.28 \mathrm{mg} / \mathrm{L}$, $14.29 \mathrm{mg} / \mathrm{L}$, and $12.23 \mathrm{mg} / \mathrm{L}$, respectively (Fig. 2d).
Surprisingly, all three identified STs generated by YL-T3-CYP505D13 could not be detected in the fermentation extracts of G. lucidum (data not shown). Possible explanations include (1) repressed expression of cyp505d13 in G. lucidum; (2) a fast conversion of these intermediates by other enzymes; and (3) preference for other substrates by CYP505D13 in G. lucidum. It should be noted that ST-1 and ST-2 were discovered for the first time, highlighting the potential of our synthetic biology 

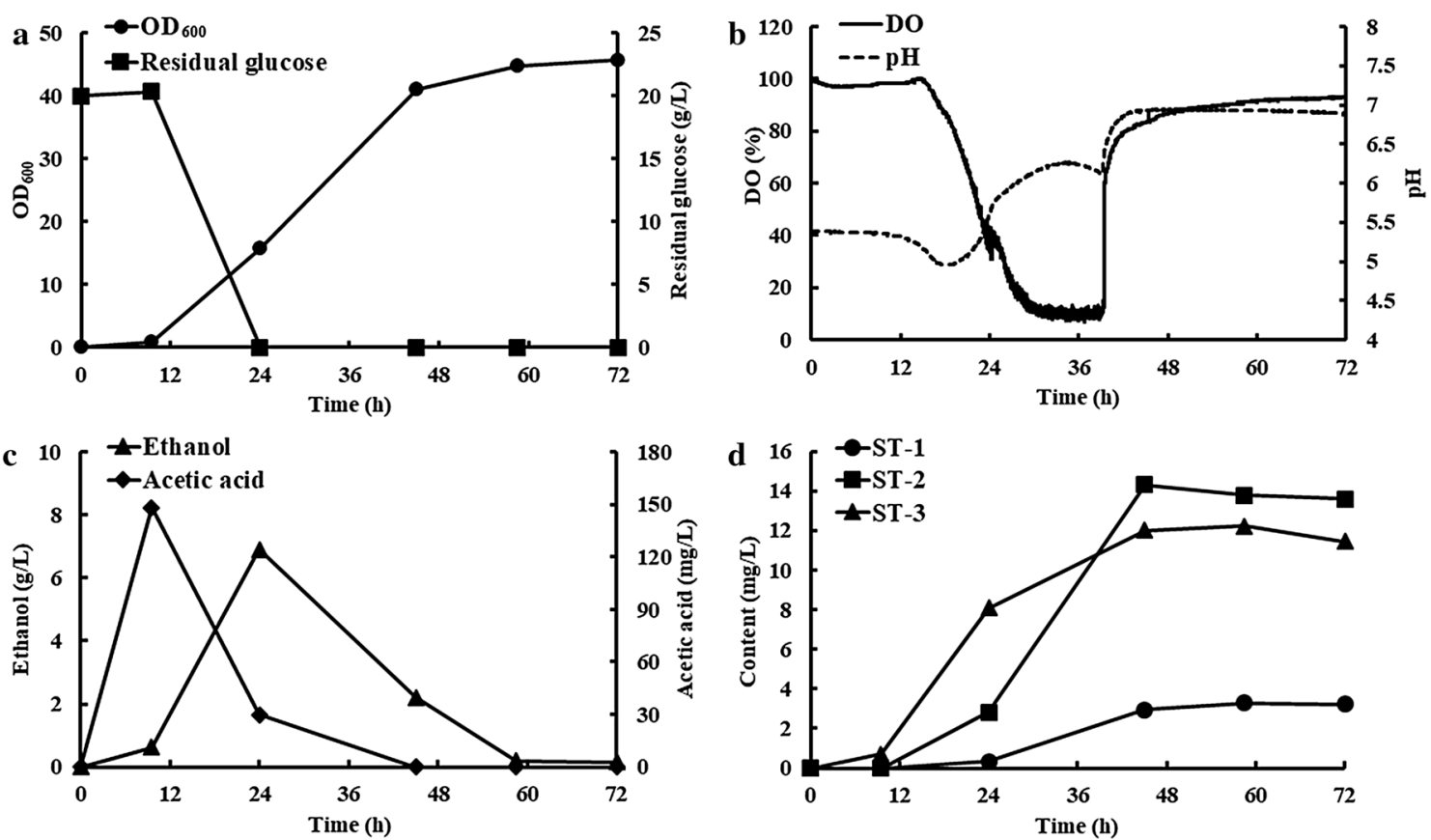

Fig. 2 Fermentation of strain YL-T3-CYP505D13 in $10 \mathrm{~L}$ bioreactor. Time profile of a residual glucose and cell growth, $\mathbf{b}$ pH and dissolved oxygen (DO), c ethanol and acetate and $\mathbf{d}$ accumulation of ST-1, ST-2, and ST-3

platform to discover novel compounds. Notably, the production yields of the STs using our yeast production platform are sufficient for future bioactivity profiling studies.

By exploring the genome of the famous traditional Chinese medicinal mushroom-G. lucidum, we discovered the first CYP-CYP505D13 responsible for ST biosynthesis using $S$. cerevisiae as a heterologous host. This discovery is not only important for ST production, but also meaningful for the generation of cyclic triterpenoids. Formation of known cyclic triterpenoids predominately involves cyclization of 2,3-oxidosqualene by terpenoid cyclase, and post-modification by other enzymes including CYPs (Dong et al. 2018). Harnessing the great power of protein engineering on terpenoid cyclases and the promiscuity of CYPs (Xiao et al. 2019), structurally diversified cyclic triterpenoids can be generated from alternative substrates, including the novel STs discovered in this study.

\section{In vitro enzymatic assay by CYP505D13}

To characterize the function of CYP505D13, we first tried and failed to get a functional purified CYP505D13 from $E$. coli or $S$. cerevisiae. Due to an unobserved membrane anchored region, CYP505D13 was predicted as a soluble CYP. However, the typical CO-shift in functional CYP was not detected in the cell lysates of Rosetta-CYP505D13 (Additional file 9: Fig. S8). It's not surprising that biosynthesis of ST-1, ST-2, and ST-3 was not detected after the cell lysates were incubated with 2,3-oxidosqualene and squalene (Additional file 10: Fig. S9).

Notably, ST-3 can also be produced by S. cerevisiae under specific conditions. This is due to the low substrate specificity of endogenous yeast squalene epoxidase ERG1 towards 2,3-oxidosqualene (Field and CE 1977; Pollier et al. 2019). Erg1 is a yeast essential gene and the corresponding knockout mutant is only viable under anaerobic conditions (Rosenfeld et al. 2003). To rule out the possibility that ERG1 expression in YL-T3 is responsible for the production of these STs, we tried to construct an erg1 knockout strain but failed after several trials (data not shown).

Next, CYP505D13 containing microsomes from YLT3-CYP505D13 were prepared and incubated with a potential substrate. Compared to the boiled microsomes, feeding microsomes with 2,3-oxidosqualene resulted in significant increase of ST-3 and a HPLC peak (with retention time (Rt) at $7.99 \mathrm{~min}$ ), decrease of squalene and 2,3-oxidosqualene, and no change in the levels of ST-1 and ST-2 (Additional file 11: Fig. S10). In addition, no production of ST-1, ST-2, and ST-3 were observed when the microsomes prepared from the control strain (YL-T3 containing void plasmids) were incubated with 2,3-oxidosqulaene (Additional file 11: Fig. S10). These results indicated that CYP505D13 may catalyze the epoxidation of 2,3-oxidosqualene (squalene) to generate ST-3, while 
ST-1 and ST-2 are not the direct reaction products of CYP505D13.

Many CYP505 family members are able to oxidize different forms of fatty acids (a straight aliphatic chain from C9 to C20) (Baker et al. 2017; Kitazume et al. 2002; Nakayama et al. 1996), with similar chemical structures to squalene (a straight chain with C30). Interestingly, CYP505 proteins are naturally fused with a cytochrome P450 reductase (CPR) to execute efficient electron transfer, displaying a higher catalytic kinetics compared to those CYPs without a CPR domain (Bernhardt and Urlacher 2014). To our knowledge, no CYP was reported to be active against long-chain substrates with more than C26 (Hardwick 2008), not mentioned to CYP505 family members. Our study indicated CYP505D13 is a subterminal epoxidase (catalyzing epoxidation between $\omega-1$ and $\omega-2)$. This seems to match with the catalytic characteristics of known CYP505 proteins, which prefer to hydroxylate at positions from $\omega$ to $\omega-3$ (Baker et al. 2017; Kitazume et al. 2002; Nakayama et al. 1996).

\section{Conclusion}

Using S. cerevisiae as a synthetic biology platform, we have showed that G. lucidum CYP505D13 is responsible for ST biosynthesis and identified two new STs [4,8-dihydroxy-22,23-oxidosqualene (ST-1), 8-hydroxy-2,3;22,23squalene dioxide (ST-2)] in addition to 2,3;22,23-squalene dioxide (ST-3). Overall, this work provides an alternative to discover STs and facilitate their efficient bioproduction and application.

\section{Additional files}

Additional file 1: Table S1. Primers used in this study.

Additional file 2: Fig. S1. MS spectra of peaks 1, 2, 3, 4, 5, 6, 7, 8, 9, 10, 12 , 14, 15, 16, 17, 18 and 19 as indicated in Fig. 1 a.

Additional file 3: Fig. S2. ${ }^{13} \mathrm{C}-\mathrm{NMR}$ spectra of (A) 1, (B) 2 and (C) 3.

Additional file 4: Fig. S3. ${ }^{1} \mathrm{H}-\mathrm{NMR}$ spectra of (A) 1, (B) 2 and (C) $\mathbf{3}$.

Additional file 5: Fig. S4. Distortionless enhancement by polarization transfer-135 (DEPT-135) spectra of (A) 1, (B) 2 and (C) 3.

Additional file 6: Fig. S5. Heteronuclear single quantum coherence (HSQC) spectra of (A) $\mathbf{1}$, (B) $\mathbf{2}$ and (C) $\mathbf{3}$.

Additional file 7: Fig. S6. Heteronuclear multiple-bond correlation $(\mathrm{HMBC})$ spectra of (A) $\mathbf{1},(\mathrm{B}) \mathbf{2}$ and (C) $\mathbf{3}$.

Additional file 8: Fig. S7. Homonuclear correlation spectroscopy (COSY) spectra of (A) $\mathbf{1}$, (B) $\mathbf{2}$ and (C) $\mathbf{3}$.

Additional file 9: Fig. S8. Expression of CYP505D13 in E. coli Rosetta ${ }^{T M}$ (DE3). (A) SDS-PAGE analysis and (B) carbon monoxide absorption spectrum of cell lysates of IPTG induced Rosetta-CYP505D13. M, marker; SF, soluble fractions; IF, insoluble fractions. Red arrows indicated the target protein CYP505D13.

Additional file 10: Fig. S9. HPLC analyses of in vitro enzymatic reactions catalyzed by CYP505D13. Crude enzymes from Rosetta-CYP505D13 (blue line) and the inactivated control (red line) were reacted with $50 \mu \mathrm{M}(\mathrm{A})$ 2,3-oxidosqualene and (B) squalene.

Additional file 11: Fig. S10. HPLC analyses of in vitro enzymatic reactions catalyzed by CYP505D13. Microsomes from YL-T3-CYP505D13 (blue line), inactive microsomes from YL-T3-CYP505D13 (red line) or microsomes from control strain (YL-T3 containing void plasmids, black line) were reacted with $50 \mu \mathrm{M}$ 2,3-oxidosqualene.

\section{Abbreviations}

STs: squalene-type triterpenoids; MVA: mevalonate; MEP: 2-C-methyl-D-erythritol 4-phosphate; CYPs: cytochrome P450s; CDS: coding sequence; IPTG: isopropyl $\beta$-D-1-thiogalactopyranoside; HRAPCl: high resolution atmospheric pressure chemical ionization; ST-3: 2,3; 22,23-squalene dioxide; ST-2: 8-hydroxy-2,3; 22,23-squalene dioxide; ST-1: 4,8-dihydroxy-22,23-oxidosqualene; CPR:

cytochrome $\mathrm{P} 450$ reductase.

\section{Acknowledgements}

We thank Prof. Jian-Jiang Zhong (Shanghai Jiao Tong University) for his helpful suggestion on this study.

\section{Authors' contributions}

$H X$ and SJL designed the experiments. XS performed experiments with partial participation by HX and WFW. SWL, XZW, and SJL determined the chemical structures of ST-1, ST-2, and ST-3. HX prepared the draft with assistance from $\mathrm{XS}$ and XZW. HX and SJL finalized the manuscript. All authors concur with the submission and have seen a draft copy of the manuscript and agree with its publication. All authors read and approved the final manuscript.

\section{Funding}

This work was supported by the National Natural Science Foundation of China (No. 31600071) and Shanghai Municipal Natural Science Foundation (Nos. 17ZR1448900, 18ZR1420300).

\section{Availability of data and materials}

They are included within the article and its additional files.

\section{Ethics approval and consent to participate}

Not applicable.

\section{Consent for publication}

Not applicable.

\section{Competing interests}

The authors declare no competing financial interests.

\section{Author details}

${ }^{1}$ State Key Laboratory of Microbial Metabolism, Joint International Research Laboratory of Metabolic \& Developmental Sciences, and Laboratory of Molecular Biochemical Engineering, School of Life Sciences and Biotechnology, Shanghai Jiao Tong University, 800 Dong-chuan Road, Shanghai 200240, China. ${ }^{2}$ State Key Laboratory of Applied Organic Chemistry, College of Chemistry and Chemical Engineering, Lanzhou University, Lanzhou 730000, China.

Received: 16 April 2019 Accepted: 21 May 2019

Published online: 29 May 2019

\section{References}

Baker GJ, Girvan HM, Matthews S, McLean KJ, Golovanova M, Waltham TN, Rigby SEJ, Nelson DR, Blankley RT, Munro AW (2017) Expression, purification, and biochemical characterization of the flavocytochrome P450 CYP505A30 from Myceliophthora thermophila. ACS Omega 2(8):4705-4724

Bernhardt R, Urlacher VB (2014) Cytochromes P450 as promising catalysts for biotechnological application: chances and limitations. Appl Microbiol Biotechnol 98(14):6185-6203

Brill E, Hannemann F, Zapp J, Bruning G, Jauch J, Bernhardt R (2014) A new cytochrome P450system from Bacillus megaterium DSM319 for the 
hydroxylation of 11-keto-beta-boswellic acid (KBA). Appl Microbiol Biotechnol 98(4):1701-1717

Cen-Pacheco F, Villa-Pulgarin JA, Mollinedo F, Norte M, Daranas AH, Fernandez JJ (2011) Cytotoxic oxasqualenoids from the red alga Laurencia viridis. Eur J Med Chem 46(8):3302-3308

Chen ZM, Wang SL (2015) Two new compounds from cultures of the basidiomycete Antrodiella albocinnamomea. Nat Prod Res 29(21):1985-1989

Chen S, Xu J, Liu C, Zhu Y, Nelson DR, Zhou S, Li C, Wang L, Guo X, Sun Y, Luo H, LiY, Song J, Henrissat B, Levasseur A, Qian J, Li J, Luo X, Shi L, He L, Xiang L, Xu X, Niu Y, Li Q, Han MV, Yan H, Zhang J, Chen H, Lv A, Wang Z, Liu M, Schwartz DC, Sun C (2012) Genome sequence of the model medicinal mushroom Ganoderma lucidum. Nat Commun 3:913

Chudzik M, Korzonek-Szlacheta I, Krol W (2015) Triterpenes as potentially cytotoxic compounds. Molecules 20(1):1610-1625

Dai Z, Liu Y, Sun Z, Wang D, Qu G, Ma X, Fan F, Zhang L, Li S, Zhang X (2019) Identification of a novel cytochrome P450 enzyme that catalyzes the $\mathrm{C}-2$ a hydroxylation of pentacyclic triterpenoids and its application in yeast cell factories. Metab Eng 51:70-78

Dong L, Pollier J, Bassard JE, Ntallas G, Almeida A, Lazaridi E, Khakimov B, Arendt P, de Oliveira LS, Lota F, Goossens A, Michoux F, Bak S (2018) Co-expression of squalene epoxidases with triterpene cyclases boosts production of triterpenoids in plants and yeast. Metab Eng 49:1-12

Field RB, CE H (1977) Isolation of 2,3;22,23-dioxidosqualene and 24,25-oxidolanosterol from yeast. Arch Biochem Biophys 180(2):465-471

Gietz RD, Schiestl RH (2007) High-efficiency yeast transformation using the LiAc/SS carrier DNA/PEG method. Nat Protoc 2(1):31-34

Guengerich FP, Martin MV, Sohl CD, Cheng Q (2009) Measurement of cytochrome P450 and NADPH-cytochrome P450 reductase. Nat Protoc 4(9):1245-1251

Han JY, Kim HJ, Kwon YS, Choi YE (2011) The Cyt P450 enzyme CYP716A47 catalyzes the formation of protopanaxadiol from dammarenediol-II during ginsenoside biosynthesis in Panax ginseng. Plant Cell Physiol 52(12):2062-2073

Han JY, Hwang HS, Choi SW, Kim HJ, Choi YE (2012) Cytochrome P450 CYP716A53v2 catalyzes the formation of protopanaxatriol from protopanaxadiol during ginsenoside biosynthesis in Panax ginseng. Plant Cell Physiol 53(9):1535-1545

Hardwick JP (2008) Cytochrome P450 omega hydroxylase (CYP4) function in fatty acid metabolism and metabolic diseases. Biochem Pharmacol 75(12):2263-2275

José-Luis A, Josefina C, Francrsco S, Fnchez B, Angel M (1992) 2,3:18,19-dioxidosqualene: synthesis and activity as a potent inhibitor of 2,3-oxidosqualene-lanosterol cyclase in rat liver microsomes. Bioorganic Med Chem Lett 2(10):1239-1242

Kelly SL, Lamb DC, Cannieux M, Greetham D, Jackson CJ, Marczylo T, Ugochukwu C, Kelly DE (2001) An old activity in the cytochrome P450superfamily (CYP51) and a new story of drugs and resistance. Biochem Soc Trans 29:122-128

Kim SK, Karadeniz F (2012) Biological importance and applications of squalene and squalane. Adv Food Nutr Res 65:223-233

Kitazume T, Tanaka A, Takaya N, Nakamura A, Matsuyama S, Suzuki T, Shoun $H$ (2002) Kinetic analysis of hydroxylation of saturated fatty acids by recombinant P450foxy produced by an Escherichia coli expression system. Eur J Biochem 269(8):2075-2082

Kouam SF, Kusari S, Lamshoft M, Tatuedom OK, Spiteller M (2012) Sapelenins G-J, acyclic triterpenoids with strong anti-inflammatory activities from the bark of the Cameroonian medicinal plant Entandrophragma cylindricum. Phytochemistry 83:79-86

Nakayama N, Takemae A, Shoun H (1996) Cytochrome P450foxy, a catalytically self-sufficient fatty acid hydroxylase of the fungus Fusarium oxysporum. $J$ Biochem 119(3):435-440

Nguyen HT, Chau VM, Phan VK, Hoang TH, Nguyen HN, Nguyen XC, Tran HQ, Nguyen XN, Hyun JH, Kang HK, Kim YH (2010) Chemical components from the Vietnamese soft coral Lobophytum sp. Arch Pharm Res 33(4):503-508

Pollier J, Vancaester E, Kuzhiumparambil U, Vickers CE, Vandepoele K, Goossens A, Fabris M (2019) A widespread alternative squalene epoxidase participates in eukaryote steroid biosynthesis. Nat Microbiol 4(2):226-233

Rascon-Valenzuela LA, Velazquez-Contreras C, Garibay-Escobar A, RoblesZepeda RE (2017) Triterpenoids: synthesis, use in cancer treatment and other biological activities, vol 106. Nova Science Pulishers, New York

Rosenfeld E, Beauvoit B, Blondin B, Salmon JM (2003) Oxygen consumption by anaerobic Saccharomyces cerevisiae under enological conditions: effect on fermentation kinetics. Appl Environ Microbiol 69(1):113-121

Seki H, Sawai S, Ohyama K, Mizutani M, Ohnishi T, Sudo H, Fukushima EO, Akashi T, Aoki T, Saito K, Muranaka T (2011) Triterpene functional genomics in licorice for identification of CYP72A154 involved in the biosynthesis of glycyrrhizin. Plant Cell 23(11):4112-4123

Spanova M, Daum G (2011) Squalene_-biochemistry, molecular biology, process biotechnology, and applications. Eur J Lipid Sci Tech 113(11):1299-1320

Valverde ME, Hernandez-Perez T, Paredes-Lopez O (2015) Edible mushrooms: improving human health and promoting quality life. Int J Microbiol 2015:376-387

Wang JB, Li G, Reetz MT (2017) Enzymatic site-selectivity enabled by structureguided directed evolution. Chem Commun 53(28):3916-3928

Wang WF, Xiao H, Zhong JJ (2018) Biosynthesis of a ganoderic acid in Saccharomyces cerevisiae by expressing a cytochrome P450 gene from Ganoderma lucidum. Biotechnol Bioeng 115(7):1842-1854

Warleta F, Campos M, Allouche Y, Sanchez-Quesada C, Ruiz-Mora J, Beltran G, Gaforio JJ (2010) Squalene protects against oxidative DNA damage in MCF10A human mammary epithelial cells but not in MCF7 and MDAMB-231 human breast cancer cells. Food Chem Toxicol 48(4):1092-1100

Xiao H, Zhang Y, Wang M (2019) Discovery and engineering of cytochrome P450s for terpenoid biosynthesis. Trends Biotechnol 37(6):618-631

Yasumoto S, Seki H, Shimizu Y, Fukushima EO, Muranaka T (2017) Functional characterization of CYP716 family P450 enzymes in triterpenoid biosynthesis in tomato. Front Plant Sci 8:21

\section{Publisher's Note}

Springer Nature remains neutral with regard to jurisdictional claims in published maps and institutional affiliations.

\section{Submit your manuscript to a SpringerOpen ${ }^{\circ}$ journal and benefit from:}

- Convenient online submission

- Rigorous peer review

- Open access: articles freely available online

- High visibility within the field

- Retaining the copyright to your article

Submit your next manuscript at $\boldsymbol{\nabla}$ springeropen.com 